\title{
PENGUKURAN KINERJA KOMITMEN ORGANISASI PADA KINERJA MANAJERIAL DENGAN FINANCIAL DISTRESS SEBAGAI PEMODERASI
}

\author{
Uum Helmina Ch. ${ }^{1}$, Andri Wskita Adji ${ }^{2}$ \\ Universitas Sarjanawiyata Tamansiswa
}

\begin{abstract}
Business competition in this day and age is considered to be very tight, increasing the efforts of UMKM to improve managerial performance. Starting from the improvement from the management side to thr improvement of service to consumers. Long term goal: study the effect of the performance measurement system, organizational commitment on managerial performance with financial distress as a moderating variable in UMKM Yogyakarta. The method used to achieve the goal is to distribute questionnaire are processed using to the SEM-PLS methods and analyzed. The data that can be obtained from $88 \%$ of the total data are 88 respondents. The results of this study state about positive performance measurements of managerial performance. Organizational commitment does not lead to managerial performance. Financial distress do not affect managerial performance. Then, performance measurement positively influences managerial performance with financial distress as predictor of moderation. And, finally organizational commitment to managerial performance with financial distress as homologous moderator or potential moderation.
\end{abstract}

Keywords : Performance Measurement, Organizational Commitment, Financial Distress, Managerial Performance

Correspondence to : helmina.uum@ustjogja.ac.id

\section{PENDAHULUAN}

Ujung tombok perusahaan adalah produk/jasa yang dihasilkan dan dijual kepada konsumen. Produk/jasa inilah yang akan menjadi alat untuk menarik konsumen agar semakin tertarik dengan apa yang kita tawarkan. Semakin tinggi kualitas produk/jasa yang ditawarkan, maka semakin meningkat daya tari konsumen pada produk/jasa ini. Bagi sebagian orang tidak akan memandang dari segi harga produk/jasa, melainkan dari segi kualitas produk/jasa.

Guna mendapatkan produk/jasa yang diharapkan maka dibutuhkan sumber daya manusia termasuk para manajer yang mempunyai kualifikasi sesuai dengan kompetensinya masing-masing bidang. Setiap periode akan di ukur kinerja manajer dalam perusahaan sehingga dapat menghasilkan karya yang sesuai dengan harapan perusahaan. Menurut Mulyadi, (2009) pengukuran kinerja adalah penentuan secara periodik efektifitas operasional suatu organisasi dan karyawan berdasarkan sasaran, standar dan kriteria yang telah ditetapkan sebelumnya. Dengan adanya penilaian kinerja, manajer dapat merencanakan yang akan dilakukan dalam mencapai tujuan yang telah ditetapkan. Sistem dalam pengukuran kinerja ini dapat mendeteksi kekurangan sehingga akan segera dilakukan evaluasi dan tindak lanjut berikutnya. 
Kemudian untuk mencapai tujuan bersama, maka diperlukan penyatuan visi,misi, dan strategi diikuti dengan perencanaan yang matang. Hal ini dapat diimplementasikan dalam strategi perencanaan suatu produk yang sesuai dengan keinginan pasar. Komitmen ini akan mengikat manajemen untuk tidak keluar dari tujuan bersama sehingga kinerja manajemen dapat semakin meningkat. Dalam meingkatkan kinerja dalam sebuah manajemen diperlukan kekuatan dari dalam (internal) organisasi Hal ini sependapat dengan Aristiani \& Mimba (2019), kinerja para manajer akan meningkat ketika para manajer mempunyai komitmen organisasi yang kuat.

Selama perjalanan operasional banyak permasalahan yang akan timbul. Dan permasalahan keuangan masih mendominasi sebagai masalah bagi perusahaan dalam berjalannya usaha. Hal ini dikarenakan masalah keuangan (financial distress) dapat mempunyai dampak yang menyeluruh ke setiap aspek perusahaan. Mulai dari kegiatan produksi yang akan macet ketika tidak ada supply cash guna membiayai produk yang akan dijual, dan pada akhirnya akan berdampak juga pada kualitas kinerja manajerialnya. Kinerja seorang pegawai akan tergantung pada kondisi internal dan eksternal yang melingkupi individu organisasi dalam melakukan pekerjaan (Putri, 2010). Jika perusahan mengalami masalah pada keuangannya dalam kaitannya pemberian upah tambahan (insentif), maka akan mempengaruhi kualitas kinerja pegawai. Berdasarkan latar belakang ini, penulis bertujuan menguji sistem pengukur kinerja dan komitmen organisasi akan mempengaruhi kinerja manajemen dengan financial distress sebagai variabel moderasi.

\section{METODE PENELITIAN}

Berdasarkan tujuan dan hipotesis yang telah dirumuskan maka penelitian ini termasuk penellitian kausatif. Penelitian ini menggunakan sumber data primer yang diperoleh melalui survey. Populasi penelitian ini adalah pengusaha yang termasuk dalam kriteria UMKM dengan omset per tahun kurang dari 4.8 miliyar. Sampelnya adalah pengusaha UMKM yang berada di wilayah DIY dengan kriteria mempunyai pegawai yang sudah bekerja sebab dalam penilaian pegawai dapat dievaluasi jika sudah bekerja minimal 1 tahun atau 1 periode penilaian. Dengan demikian, penelitian ini termasuk dalam kategori purposive sampling.

\section{HASIL PENELITIAN}

Penelitian ini menggunakan data primer yang berasal dari kuisioner yang diisi oleh pemilik UMKM melalui aplikasi google form. Kuisioner berhasil terkumpul sebanyak 88 kuisioner yang dapat digunakan dalam penelitian ini. Namun dalam pengolahan data, sebanyak 9 data dari responden merupakan data outlier sehingga harus dikeluarkan dari model penelitian.

TABEL 1. Hasil Uji Deskripsi Responden

\begin{tabular}{lll}
\hline Keterangan & Jumlah & Persentase \\
\hline $\begin{array}{l}\text { Kuesioner yang } \\
\text { diedarkan }\end{array}$ & 88 & $100 \%$ \\
\hline $\begin{array}{l}\text { Kuesioner yang } \\
\text { kembali }\end{array}$ & 88 & $100 \%$ \\
\hline $\begin{array}{l}\text { Kuesioner yang tidak } \\
\text { bisa digunakan }\end{array}$ & 9 & $10,2 \%$ \\
\hline $\begin{array}{l}\text { Total Kuesioner yang } \\
\text { digunakan }\end{array}$ & 79 & $89,8 \%$ \\
\hline $\begin{array}{l}\text { Sumber: data primer yang diolah (2019) } \\
\end{array}$
\end{tabular}

\section{Uji Kualitas Data}

Penelitian dapat dinyatakan mempunyai data yang layak digunakan (valid) sebagai sampel apabila nilai Faktor 
loading (outer loading) lebih besar dari 0,5 dan nilai Average VarianceExtracted (AVE) lebih besar dari 0,5. Selanjutnya untuk uji reliabilitas dapat diketahui dengan melihat nilai Cronbach Alpha dan Composite Reiability, apabila lebih dari 0,6 maka data dinyatakan reliabel. Berikut ini merupakan hasil dari uji validitas dan reliabilitas.

1. Hasil Uji Validitas

Uji validitas dilakukan dengan menggunakan evaluasi measurement (outer) model yaitu dengan menggunakan convergent validity besarnya loading factor untuk masing-masing >0,50 terhadap variabel yang dituju. Berikut output model pengukuran atau outer model dengan PLS.

TABEL 2. Convergen Validity

\begin{tabular}{|c|c|c|c|c|c|c|}
\hline & $\begin{array}{l}\text { Moder } \\
\text { ating } \\
\text { effect } \\
1\end{array}$ & $\begin{array}{l}\text { Mod } \\
\text { erati } \\
\text { ng } \\
\text { effec } \\
\text { t } 2\end{array}$ & SPK & FD & KM & $\mathrm{KO}$ \\
\hline $\begin{array}{l}\text { SPK } \\
\text { *FD }\end{array}$ & 0.967 & & & & & \\
\hline $\begin{array}{l}\mathrm{KO}^{*} \\
\mathrm{FD}\end{array}$ & & $\begin{array}{l}1.00 \\
6\end{array}$ & & & & \\
\hline $\mathrm{X} 1.1$ & & & $\begin{array}{l}0.92 \\
1\end{array}$ & & & \\
\hline X1.2 & & & $\begin{array}{l}0.82 \\
7\end{array}$ & & & \\
\hline $\mathrm{X} 2.1$ & & & & & & $\begin{array}{l}0.92 \\
3\end{array}$ \\
\hline $\mathrm{X} 2.2$ & & & & & & $\begin{array}{l}0.51 \\
4\end{array}$ \\
\hline $\mathrm{X} 2.3$ & & & & & & $\begin{array}{l}0.80 \\
8 \\
\end{array}$ \\
\hline $\mathrm{Y} 1$ & & & & & $\begin{array}{l}0.79 \\
1\end{array}$ & \\
\hline Y2 & & & & & $\begin{array}{l}0.74 \\
7\end{array}$ & \\
\hline Y3 & & & & & $\begin{array}{l}0.70 \\
0\end{array}$ & \\
\hline Y4 & & & & & $\begin{array}{l}0.71 \\
1 \\
\end{array}$ & \\
\hline $\mathrm{Z1}$ & & & & $\begin{array}{l}0.88 \\
1\end{array}$ & & \\
\hline $\mathrm{Z} 2$ & & & & $\begin{array}{l}0.87 \\
1 \\
\end{array}$ & & \\
\hline $\mathrm{Z3}$ & & & & $\begin{array}{l}0.87 \\
9\end{array}$ & & \\
\hline
\end{tabular}

Sumber: data primer yang diolah (2019)

Berdasarkan tabel di atas bahwa indikator reflektif cocok digunakan untuk mengukur persepsi sehingga penelitian ini menggunakan indikator reflektif. Tabel di atas menunjukkan bahwa loading factor memberikan nilai di atas nilai yang disarankan yaitu sebesar 0,5. Nilai paling kecil adalah sebesar 0.514 untuk indicator Y3. Berarti indikator yang dipergunakan dalam penelitian ini adalah valid atau telah memenuhi convergent validity. Berikut adalah diagram loading factor masingmasing indikator dalam model penelitian:

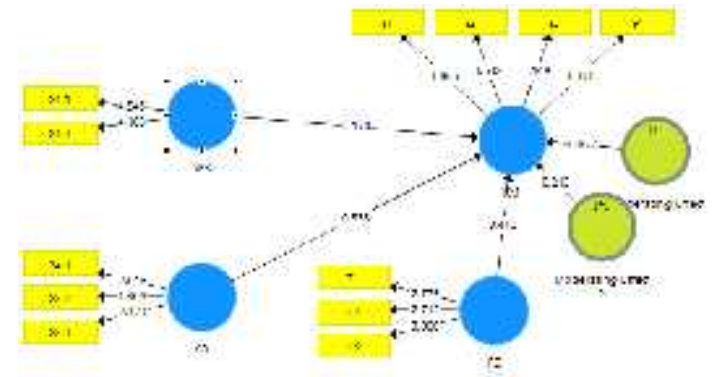

Gambar 1. Loading Factor

Setelah melakukan uji validitas untuk setiap butir pernyataan, dapat dilakukan uji validitas untuk setiap variabel. Dengan mengacu pada rule of tumb dari AVE dimana nilai AVE lebih besar dari 0,5 maka variabel dinyatakan valid dan layak untuk melakukan uji selanjutnya. Berikut tabel hasil uji AVE yang sudah diolah.

TABEL 3. Hasil Uji Average Variance Extracted (AVE)

\begin{tabular}{lll}
\hline Variabel & Rule Tumbs & Nilai (AVE) \\
\hline FD & 0.5 & 0.790 \\
\hline KM & 0.5 & 0.587 \\
\hline KO & 0.5 & 0.646 \\
\hline Moderating effect 1 & 0.5 & 1.000 \\
\hline Moderating effect 2 & 0.5 & 1.000 \\
\hline SPK & 0.5 & 0.775 \\
\hline Sumber: data primer diolah 2019 &
\end{tabular}

2. Hasil Uji Realibitas

Penelitian ini dapat dilanjutkan jika data yang dipergunakan dinyatakan reliabel. Syarat dapat dinyatakan reliabel jika nilai Cronbach Alpha dan Composite Reliability lebih besar dari 0,7. Tabel 5 dapat dilihat setiap variabel memiliki nilai Cronbach Alpha dan Composite Reliability lebih besar 0,7 menandakan bahwa 
internalconsistencydari variabel dependen dan variabel independen memiliki realiabilitas yang baik.

TABEL 4. Hasil Uji Reliabilitas

\begin{tabular}{|c|c|c|}
\hline Variabel & $\begin{array}{l}\text { Cronbach } \\
\text { Alpha }\end{array}$ & $\begin{array}{l}\text { Composite } \\
\text { Reliability }\end{array}$ \\
\hline$F D$ & 0.867 & 0.919 \\
\hline KM & 0.759 & 0.770 \\
\hline KO & 0.742 & 0.845 \\
\hline SPK & 0.709 & 0.873 \\
\hline Moderating effect 1 & 1.000 & 1.000 \\
\hline Moderating effect 2 & 1.000 & 1.000 \\
\hline
\end{tabular}

\section{PEMBAHASAN}

Pengukuran Kinerja berpengaruh positif terhadap Kinerja Manajerial.

Dari pengujian hipotesis yang dilakukan sebelumnya, didapatkan hasil yaitu $\mathrm{H} 1$ diterima yang berarti bahwa pengukuran kinerja berpengaruh positif signifikan dengan kinerja manajerial. Hal ini menandakan bahwa sistem yang diterapkan perusahaan dalam mengukur dan menilai kinerja dari para karyawan khususnya manajer dapat mempengaruhi kualitas kinerja manajerial perusahaan pada umumnya. Dan teori kontijensi yang digunakan dalam penelitian ini sesuai yang artinya dalam perusahaan menerapkan sistem ini berdasarkan kondisi yang terjadi pada saat itu. Hasil ini sesuai dengan penelitian sebelumnya yang dilakukan oleh Flantika (2009) yang menyatakan bahwa Sistem Pengukuran Kinerja berpengaruh signifikan positif terhadap Kinerja Manajerial.

Komitmen Organisasi berpengaruh positif terhadap Kinerja Manajerial.

Dari pengujian hipotesis yang dilakukan sebelumnya, didapatkan hasil yaitu $\mathrm{H} 2$ ditolak. Hal ini menandakan bahwa karyawan tidak mempunyai fokus bersama untuk mengembangkan tempat dia bekerja. Beberapa karyawan hanya bekerja dengan anggapan bahwa bekerja hanya sekedar untuk memperoleh nafkah saja dan berusaha untuk tidak membuat kesalahan. Hal ini menyebabkan organisasi di dalam perusahaan tidak mengalami perkembangan di dalam kegiatan operasional maupun kegiatan sosail lainnya.

Financial Distress (Kesulitan Keuangan) berpengaruh negatif terhadap Kinerja Manajerial.

Dari pengujian hipotesis yang dilakukan sebelumnya, didapatkan hasil yaitu $\mathrm{H} 3$ ditolak. Hal ini menandakan bahwa kesulitan keuangan yang terjadi pada perusahaan tidak akan menurunkan kualitas kinerja para karyawan. Menurut hasil kuesioner, responden menanggapi bahwa utang yang besar dapat tidak akan merubah motivasi perusahaan dalam meningkatkan laba sehingga dalam peningkatan kinerja karyawann juga akan tetap sama seperti biasanya.

Pengukuran Kinerja berpengaruh positf terhadap Kinerja Manajerial dimoderasi oleh Financial Distress.

Dari pengujian hipotesis yang dilakukan sebelumnya, didapatkan hasil yaitu $\mathrm{H} 4$ ditolak. Namun pada pengujian H1 hasilnya diterima berarti Financial Distress dapat dikategorikan sebagai predictor moderation atau Financial Distress hanya dapat berperan sebagai variabel predictor (independen) dalam model hubungan yang dibentuk. Menurut hasil kuesioner, responden menanggapi bahwa karyawan akan bekerja sesuai dengan porsi masing-masing meski perusahaan dalam keadaan mempunyai utang kepada pihak ketiga atau semacamnya. Karyawan lebih cenderung acuh tak acuh karena mempunyai pemikiran bahwa bekerja 
sesuai jatah dan sesuai dengan kompensasi tanpa memperdulikan konsidi perusahaan.

Komitmen Organisasi berpengaruh positif terhadap Kinerja Manajerial dimoderasi oleh Financial Distress.

Dari pengujian hipotesis yang dilakukan sebelumnya, didapatkan hasil yaitu $\mathrm{H} 4$ ditolak. Namun pada pengujian H2 hasilnya ditolak. Hal ini menandakan bahwa Financial Distress dapat dikategorikan sebagai homologiser moderator atau moderasi potensial yang berarti bahwa Financial Distress berpotensi menjadi variabel moderasi. Menurut hasil kuesioner, responden menanggapi bahwa karyawan yang cenderung mempunyai pemikiran individualism, akan memetingkan kepentingan pribadinya tanpa ingin berempati pada kondisi perusahaan saat ini. Hal ini terjadi pada hasil kuisioner penelitian ini dan berakibat tujuan perusahaan akan sulit tercapai. Namun, akan berbeda hasil jika kesadaran karyawan mempunyai visi dan misi yang sama. Utang dan biaya yang timbul dan seberapa besarpun akan dihadapi bersama dengan mengembangkan produk dan meningkatkan kualitas diri perusahaan.

\section{SIMPULAN}

Pada tahap akhir penelitian ini yaitu menarik kesimpulan. Kesimpulannya adalah

1. Pengukuran kinerja berpengaruh positif terhadap kinerja manajerial. Jadi semakin tinggi perusahaan dalam mengevaluasi kegiatan operasional maka kinerja manajerial juga akan semakin meningkat dengan dibuktikan dengan meningkatnya laba dan dan kepuasan konsumen.

2. Komitmen organisasi tidak berpengaruh terhadap kinerja manajerial. Hal ini berarti bahwa karyawan yang tidak mempunyai visi dan misi yang sama maka akan menurunkan kinerja manajerial.

3. Financial Distress (Kesulitan Keuangan) tidak berpengaruh negatif terhadap Kinerja Manajerial. Jadi kesulitan keuangan yang terjadi pada perusahaan tidak akan menurunkan atau meningkatkan kualitas kinerja para karyawan.

4. Pengukuran Kinerja berpengaruh positf terhadap Kinerja Manajerial dimoderasi oleh Financial Distress. Dalam hal ini, Financial Distress sebagai predictor moderasi atau hanya dapat berperan sebagai variabel predictor (independen) dalam model hubungan yang dibentuk. Dengan kata lain, tidak dapat memperkuat/memperlemah hubungan antara pengukuran kinerja dengan kinerja manajerial.

5. Komitmen organisasi berpengaruh positif terhadap kinerja manajerial dimoderasi oleh financial distress. Dalam hal ini, financial distress sebagai homologiser moderator atau moderasi potensial yang berarti bahwa financial distress berpotensi menjadi variabel moderasi. Dengan kata lain, ada kemungkinan jika financial distressdapat memperkuat atau memperlemah hubungan antara komitmen organisasi dengan kinerja manajerial dan terjadi pada perusahaan tertentu dan pada keadaan tertentu.

\section{DAFTAR PUSTAKA}

Aristiani, I. A. M., \& Mimba, N. P. S. H. (2019). Pengaruh Budgetary Goal Characteristics, Komitmen Organisasi , Dan Motivasi Pada Kinerja Manajerial dengan Gaya Kepemimpinan Sebagai Variabel Moderasi. E-Jurnal Akuntansi Universitas Udayana, 27, 2322-2350. Retrieved 
https://doi.org/10.24843/EJA.2019.v27. i03.p25

Flantika, D. (2009). Pengaruh Sistem Pengukuran Kinerja, Kompensasi Dan Gaya Kepemimpinan Terhadap Kinerja Manajerial. Jurnal Akuntansi.

Gamayuni, R. R. (2011). Analisis Ketepatan Model Altman Sebagai Alat Untuk Memprediksi Kebangkrutan. Jurnal Akuntansi Dan Keuangan, 16, 176-190.

Handoko, H. (2007). Manajemen. Yogyakarta: BPFE UGM.

Haspiarti. (2012). PENGARUH PENERAPAN ANGGARAN BERBASIS KINERJA TERHADAP AKUNTABILITAS KINERJA INSTANSI PEMERINTAH (STUDI PADA PEMERINTAH KOTA PAREPARE).

MAKASSAR: repository.unhas.ac.id.

Herdiyanto, W. S. (2015). PENGARUH STRUKTUR UTANG TERHADAP KINERJA PERUSAHAAN (Studi Empiris pada Perusahaan Manufaktur Tahun 2011-2013). Diponegoro Journal of Accounting, 4(3), 531-540.

Kaplan, R. S., \& Norton, D. P. (2009). Balanced Scorecard: Menerapkan Strategi menjadi Aksi. Jakarta: Erlangga.

Kumentas, C. N. (2013). No Title. Jurnal EMBA, 1(3), 796-805.

Mardiyah, A. A., \& Listianingsih. (2005). PENGARUH SISTEM PENGUKURAN KINERJA, SISTEM REWARD, DAN PROFIT CENTER TERHADAP HUBUNGAN ANTARA TOTAL QUALITY MANAGEMENT DENGAN KINERJA MANAJERIAL. SNA VIII Solo, 565-585.

Mintje, N. (2013). Pengaruh TQM,Sistem Penghargaan dan Sistem Pengukuran Kinerja Terhadap Kinerja Manajerial pada PT. AIR MANADO. 1(3), 52-62.
Mulyadi. (2009). Sistem Terpadu Pengelolaan Kinerja Personel Berbasis Balanced Scorecard. Yogyakarta: UPPSTIM YKPN.

Narsa, I. M., \& Yuniawati, R. D. (2003). Pengaruh Interaksi Antara Total Quality Management Dengan Sistem Pengukuran Kinerja dan Sistem Penghargaan Terhadap Kinerja Manajerial Studi Empiris pada PT. Telkom Divre V Surabaya. Jurnal Akuntansi Dan Keuangan, 5(1), 18-34. https://doi.org/10.9744/jak.5.1.pp.18-34

Nasution, M. N. (2011). Manajemen Mutu Terpadu. Bogor: Ghalia Indah.

Negara, I. G. J., \& Gayatri. (2017). PENGARUH PARTISIPASI ANGGARAN, SELF-EFFICACY, SISTEM PENGUKURAN KINERJA, DAN SISTEM REWARD PADA KINERJA MANAJERIAL. E-Jurnal Akuntansi Universitas Udayana, 20.

Putri, N. D. (2010). Pengaruh Komitmen Organisasional Dan Peran Manager Keuangan Daerah Terhadap Kinerja Managerial Satuan Kerja Perangkat Daerah (Studi Pada Kabupaten Tegal). In Universitas Diponegoro. Retrieved from http://eprints.undip.ac.id/22929/

Robbins, S. P. (2008). Perilaku Organisasi. Jakarta: PT. Indeks Gramedia.

Sianipar, R. D. (2013). Pengaruh Sistem Pengukuran Kinerja dan Sistem Reward terhadap Kinerja Manajerial (Studi Empiris pada Perusahaan BUMN di Kota Padang). Ejournal.Unp.Ac.Id, 66, 37-39.

Sjahrial, D. (2007). Manajemen Keuangan. Jakarta: MItra Wijaya Media.

Sulijaya, F. (2015). Pengaruh Total Quality Management, MOtivasi Dan Komitmen Organisasi Terhadap Kinerja 
Manajemen pada PT SEKAR BUMI, TBK. XIX(03), 433-448.

Susilowati, S. (2017). Komitmen Organisasi Karyawan Universitas Dr. Soetomo Surabaya. Ekspektra, 1(1), 68-79. https://doi.org/10.25139/ekt.v1i1.90

Venusita, L. (2006). Partisipasi Anggaran dan Keterlibatan Kerja terhadap Senjangan Anggaran dengan Komitmen Organisasi sebagai Variabel Moderasi (studi pada perusahaan Industri Food and beverge di Kawasan Industri SIER). Jurnal Universitas Widya Kartika Surabaya.

Wasana, J. K. H. (2015). Pengaruh Kompetensi dan Komitmen Oganisasi pada Kinerja Manajerial Bank
Perkreditan Rakyat Sekabupaten

Gianyar. E-Jurnal Akuntansi

Universitas UdayanaJurnal Akuntansi Universitas Udayana.

Widarsono, A. (2007). Pengaruh Kualitas Informasi Manajemen Terhadap Kinerja Manajerial (Survey pada perusahaan go-publik di Jawa Barat). Jurnal Akuntansi FE Unsil, 2(2), 288-299.

Wulandari, P. (2015). Pengaruh Kepuasan Kerja dan Komitmen Organisasi Terhadap Organizational Citizenshio Behaviour. Yogyakarta.

Yuwono, et al. (2005). Psikologi Industri dan Organisasi. Surabaya: Universitas Airlangga. 